\title{
Medical agents acting on the renin-angiotensin- aldosterone axis for the treatment of heart failure
}

\author{
Hiroaki Kawano and Koichi Node \\ Hypertension Research (2010) 33, 192-193; doi:10.1038/hr.2009.232
}

$\mathrm{H}$ eart failure (HF) is the final common pathway of most cardiovascular diseases, and the incidence of HF rises in the elderly population, especially in the developed countries. ${ }^{1,2}$ HF is a syndrome characterized initially by left ventricular dysfunction that triggers countermeasures aimed to restore cardiac output. These responses are compensatory at first but eventually become part of the disease process itself, leading to further worsening of cardiac function. The traditional paradigm of HF utilized the hemodynamic model to explain cardiac disease. Thus, treatment of HF based on reductions in preload and afterload were thought to be beneficial and to improve myocardial performance. However, recent studies reported that a lot of factors, such as activation sympathetic nerve systems, neurohumoral functions, cytokine systems, and the renin-angiotensin-aldosterone axis, have an important role in the whole human body during the progression of cardiac decompensation. Thus, the hemodynamic model was gradually replaced by the neurohormonal model. Studies in the late 1980s and 1990s showed that angiotensin-converting enzyme inhibitors (ACEIs) were a pivotal treatment in the management of HF, both ameliorating hemodynamic abnormalities associated with the condition and improving survival. ${ }^{3}$ The guidelines for HF stated that ACEIs should remain the treatment of first choice in $\mathrm{HF}^{4}$

Several adverse effects of ACEIs, such as cough and angioedema, have been ascribed to increased levels of bradykinin or other kinins, because angiotensin-converting enzymes are also responsible for kinin degradation.

$\mathrm{H}$ Kawano is at the Department of Cardiovascular and Renal Medicine, Saga University Faculty of Medicine, 5-1-1 Nabeshima, Saga 8498501, Japan.

E-mail: hiroaki-kawano@fc.kuh.kumamoto-u.ac.jp
Conversely, bradykinin also has favorable vasodilatory and antitrophic effects, which may explain part of the benefits seen with ACEIs. ${ }^{5}$ Recent studies have reported that not only ACEIs but also angiotensin receptor blockers (ARBs) improved hemodynamics and reduced aldosterone and atrial natriuretic peptide levels as compared with placebo. In addition, ARBs were able to increase exercise tolerance and reduce HF symptoms. ${ }^{1,2}$ Treatment with ARBs was shown to be comparable to ACEIs in terms of their effects on leftventricular ejection fraction, neurohormonal activation, HF symptoms and exercise tolerance. $^{6}$ The OPTIMAAL trial compared the effects of losartan and captopril on mortality and other major cardiovascular events in high-risk patients with left ventricular dysfunction following acute myocardial infarction. ${ }^{7}$ The trial results did not show significant differences between ARBs and ACEIs. The VALIANT trial compared the effects of captopril with those of valsartan in patients with clinical signs of HF and/or left-ventricular dysfunction following acute myocardial infarction. ${ }^{8}$ The primary end point was death and the secondary end point was a composite of cardiovascular death, recurrent infarction or hospitalization for HF. The trial results did not show any differences between captopril and valsartan.

A double-blind, randomized study compared candesartan and placebo in patients with HF who were not receiving ACEIs. ${ }^{9}$ The study was terminated early, as significant benefit with candesartan was observed in an interim analysis. The ELITE II trial in elderly patients with HF compared the effects of losartan and captopril on all-cause mortality, sudden death and resuscitated cardiac arrest. ${ }^{10}$ The trial results did not show any differences between ARBs and ACEIs. Nevertheless, ARBs were significantly better tolerated than ACEIs.
In 1999, spironolactone, an aldosterone antagonist, was shown to reduce mortality in patients with severe HF who were already receiving ACEI. ${ }^{11}$ The selective aldosterone blocker, eplerenone, was shown to decrease the risk of death and hospitalization in patients with HF following myocardial infarction who were receiving standard treatment. ${ }^{12}$ These studies showed that the medical agents for the renin-angiotensin-aldosterone axis were essential for the treatment of HF.

The main goals of treatment for HF are to reduce the symptoms, prolong survival, improve the quality of life and prevent disease progression. Tsuchihashi-Makaya et al. ${ }^{13}$ reported that discharge use of ARBs provides comparable effects with ACEIs on outcomes in patients with HF. There are several study limitations as the authors have mentioned in the paper. Among these limitations, the most important limitation is that documentation of ACEIs or ARBs at hospital discharge does not reflect the medication use after hospital discharge and over time. Many of the clinical manifestations of HF result from excessive salt and water retention, which leads to an inappropriate volume expansion of the intravascular compartment. These factors affect the renin-angiotensin system and arginine vasopressin system. Thus, dietary restriction of sodium is recommended in all patients with the clinical syndrome of HF. During hospitalization, each patient was able to control sodium and water intake. However, it is difficult for the patient to control daily sodium and water intake after hospital discharge. Thus, the HF situation may be changing before and after hospital discharge. In the clinical field, the cause of HF is multifactorial complication, such as advanced age, hypertension, diabetes, obesity, metabolic syndrome, coronary artery disease, cardiomyopathy, renal dysfunction, anemia, rate 
and rhythm disorder, valvular heart disease, endocrinological dysfunctions, etc. ${ }^{1,2}$ All of these factors also can affect the prognosis and development of HF. ${ }^{1,2}$ The clinical physicians should know the previous evidences of each medical agent for HF, such as ACEIs, ARBs, $\beta$-blocker, vasodilator, digitalis, diuretic, antidiabetic agents, anti-metabolic syndrome agents, anti-rhythm disorder agents, etc. The clinical physicians have to choose and use the medical agents and devices for these factors according to the HF situation in each patient. In addition, to maintain the quality of life and to prevent disease progression, the physicians have to check the HF condition every time the patient visits the hospital, and have to change the medical agents in each HF situation even in the same patient during follow-up. Age advances and daily diet changes according to season. The patient's situation of HF varies during outpatient clinic follow-up. Thus, the dose and kinds of medical agents for HF always vary in the outpatient clinic after hospital discharge. Previous studies reported that, in addition to aldosterone antagonists, beta-blockers and cardiac devices, both ACEIs and ARBs have substantially improved the quality and quantity of life in patients with HF. It may be difficult to show the differences of beneficial effects between ACEIs and ARBs by simply comparing them based on the long-time follow-up of HF and its prognosis.

1 Libby P, Bonow RO, Mann DL, Zipes DP (eds). Brounwald's Heart Disease, 8th edn. Elsevier: Amsterdam, 2008, pp 611-664.

2 Fuster V, O'Rourke RA, Walsh RA, Poole Wilson P. Hurst's The Heart, 12th edn. McGraw Hill Medical, 2008, pp 724-760.

3 The CONSENSUS Trial Study Group. Effects of enalapril on mortality in severe congestive heart failure. Results of the Cooperative North Scandinavian Enalapril Survival Study (CONSENSUS). N Engl J Med 1987; 316: 1429-1435.

4 Jessup M, Abraham WT, Casey DE, Feldman AM, Francis GS, Ganiats TG, Konstam MA, Mancini DM, Rahko PS, Silver MA, Steavenson LW, Yancy CW. 2009 focused update: ACCF/AHA Guidelines for Diagnosis and Management of Heart Failure in Adults: a report of the American College of Cardiology Foundation/American Heart Association Task Force on Practice Guidelines: developed in collaboration with the International Society for Heart and Lung Transplantation. Circulation 2009; 119: 1977-2016.

5 Horning B, Kohler C, Drexler H. Role of bradykinin in mediating vascular effects of angiotensin-converting enzyme inhibitors in humans. Circulation 1997; 95: 1115-1118.

6 Lang RM, Elkayam U, Yellen LG, Krauss D, McKelvie RS, Vaughan DE, Ney DE, Makris L, Chang PI. Comparative effects of losartan and enalapril on exercise capacity and clinical status in patients with heart failure. J Am Coll Cardiol 1997; 30: 983-991.

7 Dickstein K, Kjekshus J. Effects of losartan and captopril on mortality and morbidity in high-risk patients after acute myocardial infarction: the OPTIMAAL randomized trial. Lancet 2002; 360: 752-760.
8 Pfeffer MA, McMurray JJV, Velazquez EJ, Rouleau JL, Køber L, Maggioni AP, Solomon SD, Swedberg K, de Werf FV, White H, Leimberger JD, Henis M, Edwards S, Zelenkofske S, Sellers MA, Califf RM, for the Valsartan in Acute Myocardial Infarction Trial Investigators. Valsartan captopril, or both in myocardial infarction complicated by heart failure, left ventricular dysfunction, or both. N Engl J Med 2003; 349: 1893-1906.

9 Matsumori A. Efficacy and safety of oral candesartan cilexetil in patients with congestive heart failure. Eur J Heart Fail 2003; 5: 669-677.

10 Pitt B, Poole-Wilson PA, Segal R, Martinez FA, Dickstein K, Camm AJ, Konstam MA, Riegger G, Klinger $\mathrm{GH}$, Neaton J, Sharma D, Thiyagarajan B, on behalf of the II ELITE investigators. Effect of losartan compared with captopril on mortality in patients with symptomatic heart failure; randomized trial-the losartan heart failure survival study ELITE II. Lancet 2000; 355: 1582-1587.

11 Pitt B, Zannad F, Remme WJ, Cody R, Castaigne A Perez A, Palensky J, Wittes J, for The Randomized Aldactone Evaluation Study Investigators. The effect of spironolactone on morbidity and mortality in patients with severe heart failure. N Engl J Med 1999; 341: 709-717.

12 Pitt B, Remme W, Zannad F, Neaton J, Martinez F, Roniker B, Bittman R, Hurley S, Kleiman $J$, Gatlin $M$, Eplerenone post-acute myocardial infarction heart failure efficacy survival study investigators. Eplerenone, a selective aldosterone blocker, in patients with left ventricular dysfunction after myocardial infarction. N Engl J Med 2003; 348: 1309-1321.

13 Tsuchihashi-Makaya M, Furumoto T, Kinugawa S, Hamaguchi S, Goto K, Goto D, Yamada S, Yokoshiki H, Takeshita A, Tsutsui H, JCARE-CARD Investigators. Discharge use of angiotensin receptor blockers comparable effects with angiotensin-converting inhibitors on outcomes in patients hospitalized for heart failure. Hypertension Res 2010; 33: 197-202. 